\title{
Alfred Dürr †
}

von Martin Staehelin (Göttingen)

Die Musikwissenschaft beklagt mit dem Tode von Alfred Dürr den Verlust eines der bedeutendsten Bach-Forscher des 20. Jahrhunderts.

Dürr wurde am 3. März 1918 als Sohn eines Offiziers in Charlottenburg geboren. Nach Schulbesuch in Nordhausen bestand er das Abitur an einem Berliner Gymnasium, übrigens zusammen mit Georg von Dadelsen, der, später ebenfalls Musik- und Bach-Forscher, ihm ein enger Freund sein sollte. Bald musste er Soldat werden, so dass er seine Universitätsstudien erst nach dem Ende des Zweiten Weltkriegs aufnehmen konnte: An der Universität Göttingen studierte er - in einem interessanten Studentenkreis mit Gerhard Croll, Carl Dahlhaus, Ludwig Finscher, Rudolf Stephan und anderen - Musikwissenschaft bei Rudolf Gerber sowie Klassische Philologie bei Kurt Latte und Wolf-Hartmut Friedrich. Man wird sich nicht irren, wenn man annimmt, dass die methodisch gefestigte Klassische Philologie in ihm jenen besonderen Sinn für Überlieferungsvorgänge und Textkritik weckte, den er auch in seiner musikhistorischen Arbeit so erfolgreich entfalten sollte.

Bald nach Abschluss des Studiums sollte Dürrs Berufsleben die entscheidende Weichenstellung erfahren: Das Göttinger Bach-Fest von 1950 hinterließ einen kleinen Restbetrag, den die Organisatoren an Vorarbeiten zu einer neuen Bach-Ausgabe gewendet wissen wollten. Da Dürr eben mit einer Dissertation über Bachs frühe Kantaten bei Rudolf Gerber promoviert worden war, wurde am 1. April 1951 das neugegründete Göttinger Johann-Sebastian-Bach-Institut mit Dürr als zunächst alleinigem wissenschaftlichem Mitarbeiter besetzt. Niemand ahnte damals, dass Institut und Edition eine Lebensdauer von weit über fünfzig Jahren erreichen, dass sich die Zahl der Institutsmitarbeiter im Lauf der Jahre vergrößern und sich bald auch das Leipziger Bach-Archiv dem Göttinger Institut zur editorischen Kooperation assoziieren würde. Und gewiss ahnte man damals auch nicht, dass man in Dürr den für die Bach-Edition und -Forschung überhaupt geeignetsten Wissenschaftler gewonnen hatte, den man sich hätte denken können: Seine eminente Bedeutung für die Bach-Forschung trat in den Folgejahren in zahlreichen Aufsätzen und Rezensionen, in verschiedenen Werkmonographien und, innerhalb der Neuen Bach-Ausgabe (NBA), in insgesamt dreizehn Noten- und den zugehörigen Berichtsbänden hervor, die Dürr allein vorbereitet, und sechs weiteren, die er mit einem oder mehreren Kollegen erarbeitet hatte. Einzelne dieser Editionen auf beschränktem Raum zu nennen, ist beinahe unmöglich, aber nur schon die beiden Bände mit dem Wohltemperierten Klavier - um wenigstens diese zu erwähnen - sind schlechthin großartige editorische Leistungen, vollzogen an einer extrem breiten und schwierigen Quellenlage. Zu diesem Vielen trat die wissenschaftliche Kontrolle der von Dritten vorbereiteten Bach-Manuskripte für die Edition; Dürrs Entscheidungen über Aufbau und Organisation der NBA diente auch folgenden anderen Komponisten-Gesamtausgaben zum Vorbild. Genannt werden muss auch Dürrs Herausgeberschaft am Bach-Jahrbuch 1953-1974, zusammen mit Werner Neumann. 
Von besonders breiter Wirkung wurde Dürrs umfangreicher Aufsatz „Zur Chronologie der Leipziger Vokalwerke J. S. Bachs" von 1957, der aufgrund sorgfältigster quellenkundlicher Untersuchungen zeigen konnte, dass Bach den größten Teil seiner Leipziger Kantaten schon in den ersten Jahren des Thomas-Kantorats komponiert hatte und in den beiden letzten Lebensjahrzehnten überwiegend vorhandene Kompositionen umgearbeitet, parodiert und an neuen großen Opera vor allem Zyklisches wie die Kunst der Fuge, das Musikalische Opfer, Teile der h-Moll-Messe geschaffen hatte. Damit war Spittas lange Zeit akzeptierte These von den "späten Leipziger Choralkantaten Bachs" widerlegt, mit beinahe unüberschaubar weiten Auswirkungen auf die Bach'sche Werkchronologie und Folgen für das biographische Bach-Bild.

1981 zog sich Dürr von der Leitung des Bach-Instituts zurück und zwei Jahre später trat er dort in den Ruhestand. Gleichwohl blieb er noch immer wissenschaftlich tätig. So haben viele Bach-Freunde dankbar seine Einführungsbände etwa über das Wohltemperierte Klavier, die Johannespassion und die Kantaten gelesen, meist in mehreren Auflagen bis in die letzten Jahre hinein wiederaufgelegt und à jour gehalten. Dank für seine Leistungen ist ihm von Kollegen mit Fest- und Widmungsschriften und von mehreren Universitäten mit der Verleihung eines Ehrendoktorats bezeugt worden; auch war er Mitglied der Göttinger Akademie der Wissenschaften. Der wiederholten Einladung, Honorarprofessor an der Universität Göttingen zu werden, widerstand er: Er wolle nicht unterrichten und Professor heißen, sondern seiner Pflicht zur Bach-Forschung und -Edition nachkommen, meinte er.

In dieser Haltung äußerte sich ein kennzeichnender Zug der Dürr'schen Persönlichkeit. Er war glaubwürdig bescheiden; dazu trat eine unbeirrbare Disziplin sich selber gegenüber, aber er erwartete sie auch von anderen. Und jedermann, der seine unbeirrbar klare Sprache las oder ihn reden hörte, war beeindruckt von seiner Wahrhaftigkeit: Man spürte, dass er so sprach, wie er dachte. Das konnte ihn, etwa in Rezensionen, auch zu köstlich ironischer Kritik führen: dann saßen die Pfeile, und zu Recht.

Dürr widersprach schon 1962 eindrucksvoll und entschieden dem gleichsam säkularisierten Bach-Bild, das Friedrich Blume aufgrund der neuen Dürr'schen Chronologie entworfen hatte. Es war für Dürr typisch, dass er seinen Widerspruch mit sozialhistorischen, nicht mit theologischen oder religiösen Argumenten führte, schon gar nicht mit spekulativen „zahlensymbolischen“ Deutungen Bach'scher Musik. Dabei war der auch als Kirchenmusiker und Organist Tätige ein tiefgläubiger protestantischer Christ und mit seiner Gattin regelmäßiger Kirchgänger. Man wird sich in der Annahme nicht täuschen, dass dieser Glaube ihn auch in den schweren Zeiten seines Lebens - und solche fehlten nicht - stützte und ihm zudem ein sicheres Fundament war, auf dem sich seine vielen Gaben, auch diejenigen der Wissenschaft, ruhig und unangefochten entfalten konnten. Am 7. April 2011 ist er gestorben; sit ei terra levis. 